\title{
Tratamento de sementes para manejo do percevejo-barriga-verde na cultura de soja e milho em sucessão
}

\author{
Ana Carolina Montenegro Chiesa(1), Mariana Nunes dos Santos Sismeiro(1), \\ Amarildo Pasini ${ }^{(1)}$ e Samuel Roggia ${ }^{(2)}$
}

\begin{abstract}
(1)Universidade Estadual de Londrina, Rodovia Celso Garcia Cid, PR-445, Km 380, CEP 86055-900 Londrina, PR, Brasil. E-mail: anacarol.montenegro@hotmail.com, marisismeiro@hotmail.com, pasini@uel.br (2)Embrapa Soja, Rodovia Carlos João Strass, Caixa Postal 231, CEP 86001-970 Londrina, PR, Brasil. E-mail: samuel.roggia@embrapa.br
\end{abstract}

\begin{abstract}
Resumo - O objetivo deste trabalho foi avaliar o efeito do tratamento de sementes com inseticidas sobre o manejo de Dichelops melacanthus e a produtividade da soja e do milho, cultivados em sucessão. O estudo foi realizado em campo, nas safras 2012/2013 (I) e 2013/2014 (II). Avaliaram-se os inseticidas imidacloprido, tiametoxam, tiodicarbe, fipronil e abamectina. Determinaram-se: a densidade populacional do percevejo, a produtividade de soja e milho, e a intensidade da injúria em milho. A densidade do percevejo permaneceu abaixo de um inseto por metro quadrado, na maior parte do ciclo da soja. Os picos populacionais foram observados nas primeiras semanas, após a emergência do milho, e atingiram 2,2 (safra I) e 6,7 (safra II) percevejos por metro quadrado. $\mathrm{Na}$ cultura da soja, os inseticidas não reduziram a densidade populacional do percevejo. Na cultura do milho, o imidacloprido reduziu a densidade do percevejo em $23,2 \%$ (safra I) e 38,8\% (safra II), e a injúria em $61,8 \%$ (safra I) e 26,4\% (safra II). O tiametoxam reduziu a densidade dos insetos em $27,8 \%$ (safra II) e a injúria em $42,7 \%$ (safra I). $\mathrm{O}$ tratamento de sementes com inseticidas não proporciona aumento de produtividade à soja $\mathrm{e}$ ao milho, portanto, não se justifica sua utilização nas condições deste estudo.
\end{abstract}

Termos para indexação: Dichelops melacanthus, controle químico, flutuação populacional, manejo integrado de pragas.

\section{Seed treatment for management of the green-belly stink bug in the crop succession of soybean and corn}

\begin{abstract}
The objective of this work was to evaluate the effect of seed treatment with insecticides on the management of Dichelops melacanthus on the yield of soybean and corn, grown in succession. The study was carried out in a field, in the 2012/2013 (I) and 2013/2014 (II) crop seasons. The evaluated insecticides were: imidacloprid, thiamethoxam, thiodicarb, fipronil, and abamectin. The following were determined: stink bug population density, soybean and corn yield, and corn injury. Population density remained below one stink bug per square meter, in most of the soybean cycle. Population peaks were observed in the first weeks, after corn emergence, and they reached 2.2 (crop season I) and 6.7 (crop season II) stink bugs per square meter. In the soybean crop, the insecticides did not reduce the stink bug population density. In the corn crop, imidacloprid reduced the stink bug density in $23.2 \%$ (crop season I) and 38.8\% (crop season II), and injury in $61.8 \%$ (crop season I) and $26.4 \%$ (crop season II). Thiamethoxam reduced the insect population density in $27.8 \%$ (crop season II) and injury in $42.7 \%$ (crop season I). Seed treatment with insecticides does not provide increase for soybean and corn yields, therefore, their use is not justified in this study's conditions.
\end{abstract}

Index terms: Dichelops melacanthus, chemical control, population fluctuation, integrated pest management.

\section{Introdução}

A sucessão soja-milho é um sistema de produção amplamente utilizado no Brasil. Esse sistema corresponde a cerca de $35 \%$ da produção brasileira de grãos, e a soja, Glycine max (L.) Merrill, ocupa mais de 31 milhões de hectares, enquanto o milho, Zea mays L., segunda safra, que é cultivado predominantemente após a soja, abrange cerca de 9,6 milhões de hectares (Acompanhamento..., 2016). No entanto, a adoção deste sistema proporciona condições favoráveis para o crescimento populacional de insetos polífagos como o percevejo-barriga-verde, Dichelops melacanthus (Dallas, 1851) (Hemiptera: Pentatomidae). Esse percevejo está amplamente distribuído nas principais regiões onde se pratica a sucessão soja-milho e é 
favorecido tanto pelo plantio direto, cuja palhada the oferece abrigo, como pela sucessão cultural soja-milho ou soja-trigo, que proporciona disponibilidade contínua de alimento ao longo do ano (Ávila \& Panizzi, 1995; Chocorosqui \& Panizzi, 2004; Panizzi et al., 2012; Smaniotto \& Panizzi, 2015). Ao milho, D. melacanthus causa injúria cerca de três vezes mais intensa do que o percevejo-marrom, Euschistus heros (Fabricius, 1798) (Hemiptera: Pentatomidae) (Roza-Gomes et al., 2011; Torres et al., 2013).

O tratamento de sementes com inseticidas neonicotinoides tem sido a estratégia mais adequada para evitar perdas decorrentes do ataque de D. melacanthus (Martins et al., 2009; Brustolin et al., 2011). No Brasil, além dos neonicotinoides, há outros grupos químicos utilizados em tratamento de sementes para o controle de diversas pragas em soja e milho como, entre outros, metilcarbamato de oxina (tiodicarbe), pirazol (fipronil) e avermectina (abamectina). Esses inseticidas são encontrados no mercado, de forma isolada ou associada a outros produtos, que podem ou não ter ação sobre percevejos. Com o estudo de cada ingrediente ativo, isoladamente, espera-se que seja possível o entendimento da contribuição de cada um deles, para o embasamento da elaboração de estratégias mais eficientes para o manejo e o controle da praga.

Considerando-se que $D$. melacanthus está presente na sucessão soja-milho, tem se questionado sobre o possível efeito do tratamento de sementes, em ambas as culturas, sobre o manejo populacional da praga ao longo de vários cultivos.

O objetivo deste trabalho foi avaliar o efeito do tratamento de sementes com inseticidas sobre o manejo de Dichelops melacanthus e a produtividade da soja e do milho, cultivados em sucessão.

\section{Material e Métodos}

O estudo foi realizado na Embrapa Soja, em Londrina, PR, a $23^{\circ} 12^{\prime} 15^{\prime \prime} \mathrm{S}, \quad 51^{\circ} 10^{\prime} 55^{\prime \prime} \mathrm{W}$, durante duas safras agrícolas, 2012/2013 (safra I) e 2013/2014 ( safra II), com o cultivo em sucessão de soja e de milho. Os tratamentos consistiram de diferentes ingredientes ativos, utilizados em tratamentos de sementes de soja e milho: imidacloprido, tiametoxam, tiodicarbe, fipronil, abamectina e uma testemunha sem inseticida (Tabela 1).
Utilizou-se o delineamento experimental de blocos ao acaso, com quatro repetições, cada uma delas composta por parcelas de $20 \times 20 \mathrm{~m}$, com bordas de $1 \mathrm{~m}$ entre parcelas. A semeadura da soja na safra I foi realizada em 18 de outubro de 2012, com a cultivar BRS 360 RR, e na safra II, em 28 de outubro de 2013, com a cultivar BMX-Turbo. A densidade de semeadura foi de 20 sementes por metro linear, e o espaçamento entrelinhas de 0,50 m. Em ambas as safras, a adubação de base foi realizada na linha de semeadura, com $250 \mathrm{~kg} \mathrm{ha}^{-1}$ do adubo formulado $\mathrm{N}-\mathrm{P}_{2} \mathrm{O}_{5}-\mathrm{K}_{2} \mathrm{O}$ 0-20-20.

Na safra I, o milho híbrido Celeron TL foi semeado em 18 de março de 2013, e na safra II, em 10 de março de 2014, foi semeado o híbrido DKB 330 Pro. A densidade de semeadura foi de cinco sementes por metro linear, e o espaçamento entrelinhas de $0,80 \mathrm{~m}$. Em ambas as safras, a adubação de base foi realizada na linha de semeadura, com $250 \mathrm{~kg} \mathrm{ha}^{-1}$ do adubo formulado $\mathrm{N}-\mathrm{P}_{2} \mathrm{O}_{5}-\mathrm{K}_{2} \mathrm{O}$ 8-28-16.

Imediatamente antes da semeadura, realizou-se o tratamento de sementes com os diferentes produtos em estudo. Além disso, foram feitas inoculações de Bradyrhizobium japonicum (Atmo, Microquímica,

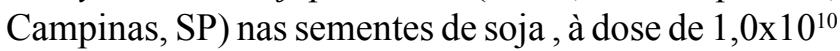
UFC kg-1 de sementes. A semeadura foi realizada com uma semeadora de parcelas, de plantio direto, com quatro linhas de soja e três de milho. Ao longo do desenvolvimento das culturas, todos os tratamentos receberam o mesmo manejo fitossanitário (Tabela 2).

Ao longo do desenvolvimento das culturas, realizouse, semanalmente, a amostragem da densidade populacional de ninfas e adultos de D. melacanthus. Em soja, as amostragens foram iniciadas na terceira e quarta semanas após a emergência das plantas, tendose realizado 12 e 10 datas de amostragem na safra I e II, respectivamente, que abrangeram a fase reprodutiva da soja, considerada como período crítico da cultura ao ataque de percevejos (Panizzi et al., 2012). Em milho, em ambas as safras, as amostragens foram realizadas por cinco semanas a partir da emergência das plantas, que corresponde ao período crítico da cultura ao ataque da praga (Cruz et al., 2011). Em soja, a amostragem foi realizada pelo método do pano de batida, em que um metro de linha de soja $\left(0,5 \mathrm{~m}^{2}\right)$ foi sacudido sobre o pano para desalojar os insetos e possibilitar a sua quantificação. Em milho, a amostragem foi realizada por meio da contagem direta dos insetos presentes nas plantas e na palhada, em uma área delimitada de 
um quadrado de $0,25 \mathrm{~m}^{2}$, com uma linha de milho de $50 \mathrm{~cm}$ de comprimento. A amostragem foi composta por quatro subamostras por parcela, em soja, e cinco, em milho, as quais foram obtidas aleatoriamente na região central da parcela.

Os dados de densidade populacional foram convertidos para percevejos por metro quadrado, e calculou-se o índice IAD (insetos acumulados diários), que considera a densidade populacional diária acumulada de indivíduos pela equação IAD $=[(0,5 \mathrm{x}$ $\left(\mathrm{P}_{\mathrm{n}}+\mathrm{P}_{\mathrm{n}+1}\right) \times \mathrm{D}$ ], em que: $\mathrm{P}_{\mathrm{n}}$ refere-se ao número de indivíduos na amostra $n ; \mathrm{P}_{\mathrm{n}+1}$ refere-se ao número de indivíduos na amostra seguinte; e D é o tempo em dias entre amostragens sucessivas.

Da segunda à quinta semana após a emergência do milho, caracterizou-se, visualmente, a injúria causada por percevejos, por meio de uma escala de notas de 0 à 4, em que: 0 indica ausência de injúria; 1 , perfurações nas folhas, sem redução de porte das plantas; 2, plantas com leve injúria no cartucho (parcialmente enrolado), com redução de porte; 3, planta com cartucho "encharutado" (preso) ou planta perfilhada; e 4, planta com cartucho seco ou morto. A avaliação foi realizada em cinco pontos fixos, previamente demarcados na região central da parcela. Cada ponto amostral foi composto por uma linha com 10 plantas de milho; atribuiu-se uma nota individual a cada planta e, a partir dessa nota foi calculada uma nota média por ponto.

Ao final do ciclo das culturas, realizou-se a colheita manual de cinco subamostras por parcela, cada uma composta por uma linha de soja ou milho com dois metros de comprimento. As subamostras foram obtidas aleatoriamente. no centro da parcela. As plantas foram

Tabela 1. Inseticidas e suas doses, aplicadas via tratamento de sementes em soja e milho, nas safras I em 2012/2013 e II em 2013/2014).

\begin{tabular}{|c|c|c|c|c|}
\hline \multirow{2}{*}{$\begin{array}{l}\text { Tratamento } \\
\text { ingrediente } \\
\text { ativo (i.a.) }\end{array}$} & \multirow[t]{2}{*}{$\begin{array}{c}\text { Produto } \\
\text { comercial }^{(1)}\end{array}$} & \multirow[t]{2}{*}{$\begin{array}{l}\text { Concentração } \\
\text { (g i.a. } L^{-1} \text { PC) }\end{array}$} & \multicolumn{2}{|c|}{$\begin{array}{c}\text { Dose do PC } \\
100 \mathrm{~kg}^{-1} \text { de sementes) }\end{array}$} \\
\hline & & & Soja & Milho \\
\hline Testemunha & Sem inseticida & - & - & - \\
\hline Imidacloprido & Gaucho FS & 600 & 200 & 350 \\
\hline Tiametoxam & Cruiser $350 \mathrm{FS}$ & 350 & 150 & 1073 \\
\hline Tiodicarbe & Tiodicarbe $350 \mathrm{SC}$ & 350 & 2000 & 2000 \\
\hline Fipronil & Standak & 250 & 200 & 1727 \\
\hline Abamectina & Avicta $500 \mathrm{FS}$ & 500 & 100 & 600 \\
\hline
\end{tabular}

(1)Produto comercial (PC) registrado no Ministério da Agricultura, Pecuária e Abastecimento (Mapa) para uso em milho e soja, com exceção de tiodicarbe $350 \mathrm{SC}$, que está registrado apenas para uso em milho. secas à temperatura ambiente para possibilitar a debulha. A partir da massa de grãos colhida de soja e milho, determinou-se a massa de mil grãos e o rendimento por hectare, tendo-se corrigido a umidade para $13 \%$. Ademais, em soja, determinou-se o percentual de massa de grãos bons, que corresponde à massa de grãos sem injúrias causadas por percevejos, grãos chochos e outras anomalias, avaliados visualmente. Em milho, quantificou-se a densidade de plantas por metro quadrado e a taxa de plantas com espigas.

Os dados obtidos foram submetidos à análise exploratória (Oliveira \& Corrêa-Ferreira, 1998), para verificar os pressupostos para a análise da variância, por meio de testes de não aditividade do modelo, normalidade dos dados, homogeneidade das variâncias, coeficiente de assimetria e curtose, tendo-se utilizado

Tabela 2. Manejo fitossanitário, realizado em soja e milho, nas safras I em 2012/2013 e II em 2013/2014.

\begin{tabular}{|c|c|c|}
\hline $\begin{array}{l}\text { Estádio }^{(1)} \\
\text { fenológico }\end{array}$ & $\begin{array}{l}\text { Produto comercial e } \\
\text { dose }^{(2)}\left(\mathrm{mL} \mathrm{ha}^{-1}\right)\end{array}$ & $\begin{array}{c}\text { Ingrediente ativo e } \\
\text { concentração }^{(2)}\left(\mathrm{g} \text { i.a. } \mathrm{L}^{-1} \mathrm{PC}\right) \\
\end{array}$ \\
\hline & \multicolumn{2}{|c|}{---------------- Soja safra I (2012/2013) ------------ } \\
\hline Pré & Glifosato $^{(3)}(2700)$ & Glifosato-sal de isopropilamina (480) \\
\hline Pré & Aurora (30) & Carfentrazona- etílica (400) \\
\hline V4 (19/11) & Glifosato $^{(3)}(2700)$ & Glifosato-sal de isopropilamina (480) \\
\hline R3 (21/12) & Belt (25) & Flubendiamida (480) \\
\hline R5.3 (22/1) & $\begin{array}{l}\text { Engeo Pleno } \\
\quad(250)\end{array}$ & $\begin{array}{l}\text { Tiametoxam+lambda-cialotrina } \\
\qquad(141+106)\end{array}$ \\
\hline R5.3 (22/1) & Priori Xtra (300) & Azoxistrobina + ciproconazol $(200+80)$ \\
\hline R6 (29/1) & $\begin{array}{l}\text { Engeo Pleno } \\
\quad(250)\end{array}$ & $\begin{array}{l}\text { Tiametoxam+lambda-cialotrina } \\
\qquad(141+106)\end{array}$ \\
\hline \multirow[t]{2}{*}{$\underline{\mathrm{R} 6(29 / 1)}$} & Priori Xtra (300) & Azoxistrobina+ciproconazol $(200+80)$ \\
\hline & \multicolumn{2}{|c|}{--oja safra II (2013/2014)--- Soja } \\
\hline Pré & Glifosato $^{(3)}(3000)$ & Glifosato-sal de isopropilamina (480) \\
\hline Pré & $\begin{array}{l}\text { U } 46 \text { D- fluid } \\
\text { (2000) }\end{array}$ & $\begin{array}{l}\text { sal de dimetilamina de ácido diclorofeno- } \\
\text { xiacético (806) }\end{array}$ \\
\hline Pré & Gramocil (2000) & Paraquat+diurom $(200+100)$ \\
\hline $\mathrm{V} 2(3 / 12)$ & Glifosato $^{(3)}(3000)$ & Glifosato-sal de isopropilamina (480) \\
\hline R2 (4/1) & Belt (50) & Flubendiamida (480) \\
\hline R3 (8/1) & Premio $(50)$ & clorantraniliprole (200) \\
\hline $\mathrm{R} 5.2(14 / 1)$ & Glifosato $^{(3)}(2800)$ & Glifosato-sal de isopropilamina (480) \\
\hline $\mathrm{R} 5.2(14 / 1)$ & Priori Xtra $(300)$ & Azoxistrobina+ciproconazol $(200+80)$ \\
\hline \multirow[t]{2}{*}{ R5.4 (31/1) } & Connect (1000) & Imidacloprido+beta-ciflutrina $(100+12,5)$ \\
\hline & \multicolumn{2}{|c|}{---------------------- Milho safra I (2012/2013)------------------ } \\
\hline V6 (3/4) & Atrazina $^{(4)}(2000)$ & Atrazina $(500)$ \\
\hline \multirow[t]{2}{*}{ V6 (3/4) } & Soberan $(240)$ & Tembotriona (420) \\
\hline & \multicolumn{2}{|c|}{ - Milho safra II (2013/2014) --- } \\
\hline V3 $(31 / 03)$ & Atrazina $^{(4)}(2000)$ & Atrazina (500) \\
\hline V3 $(31 / 03)$ & Soberan $(240)$ & Tembotriona (420) \\
\hline
\end{tabular}

(1)Pré-emergência: em 16/10/2012 (safra I) e 10/10/2013 (safra II) e entre parênteses: data de pulverização em cada safra. ${ }^{(2)}$ Dose e concentração entre parênteses. ${ }^{(3)}$ Glifosato Atanor. ${ }^{(4)}$ Atrazina Atanor 50 SC. 
o programa SAS. A não aditividade foi avaliada pelo teste de Tukey, a 5\% de probabilidade, a normalidade foi avaliada pelo teste de Shapiro-Wilk, também a 5\% de probabilidade, e a homogeneidade das variâncias foi avaliada pelo teste de Burr-Foster, tendo-se considerados homogêneos os dados com Q-calculado menor do que o Q-tabelado. Os coeficientes de assimetria e curtose foram obtidos pelo Proc Univariate (SAS), e foram considerados adequados os coeficientes inferiores ao módulo de 0,5 . Os dados que não atenderam a esses pressupostos foram ajustados até atingirem os níveis aceitáveis, pela transformação exponencial, omissão de outliers, inverso do valor $\left(\mathrm{x}^{-1}\right)$, nessa ordem de preferência, e de acordo com as características de cada conjunto de dados. Para dados percentuais, aplicaram-se as seguintes transformações $\left.(\mathrm{x} \% / 100)^{0,5},[(10-\mathrm{x} \%) / 100)^{0,5}\right]$ e arco-seno $(\mathrm{x} \% / 100)^{0,5}$, para valores distribuídos entre $0-30 \%, 70-100 \%$ e 0-100\%, respectivamente. Em seguida, os dados foram submetidos à análise de variância e, em caso de significância do teste $\mathrm{F}$ para tratamentos, as médias foram comparadas pelo teste de Tukey, a 5\% de probabilidade.

\section{Resultados e Discussão}

O percevejo Dichelops melacanthus esteve presente em ambas as culturas e suas respectivas safras (Figura 1). Sua densidade foi baixa em soja, pois não ultrapassou 1,0 percevejo por metro quadrado, com exceção da última data de amostragem da safra II, em que a densidade chegou a 2,6 percevejos por metro quadrado. Carvalho (2007) também observou que a densidade desse percevejo aumentou gradativamente, ao longo do desenvolvimento da soja, e atingiu entre 0,7 e 2,0 percevejos por metro quadrado no final do ciclo.

Em milho, na safra I, a densidade populacional foi baixa e não ultrapassou 2,2 percevejos por metro quadrado, na segunda semana após a emergência da cultura, enquanto, na safra II, o pico populacional foi atingido na terceira semana após a emergência (10 de abril,) com 6,7 percevejos por metro quadrado na testemunha. É importante destacar que as densidades populacionais observadas se aproximam de níveis observados em outros trabalhos, como os de Carvalho (2007) e Silva et al. (2013). Estes autores observaram pico populacional do percevejo em abril, com densidade de aproximadamente 4,1 e 3,0 insetos por metro quadrado, em Ponta Porã, MS, e Londrina, PR, respectivamente.

Não houve diferença estatística (Figuras 1) entre as médias dos tratamentos, quando analisados em cada data de amostragem, tanto em soja como milho, em todas safras, o que não mostra evidências de redução populacional da praga pela utilização de inseticidas em tratamento de sementes. Os dados de flutuação populacional indicam que, apesar de ter ocorrido baixa densidade populacional de percevejos em soja, essa cultura pode ter contribuído para a incidência do inseto em milho cultivado em sucessão. Particularmente, na safra II, a densidade populacional de D. melacanthus começou a aumentar a partir do final do ciclo da soja e, em milho, atingiu níveis cerca de 3,2 vezes maior em comparação à safra I. Segundo Chocorosqui \& Panizzi (2008), Silva et al. (2013) e Smaniotto \& Panizzi (2015), a soja possibilita o desenvolvimento completo, a reprodução e o aumento populacional de D. melacanthus, o que não ocorre em milho. Assim, na sucessão soja-milho, a soja pode contribuir para o desenvolvimento da população de percevejos que ocorrerá em milho cultivado em seguida. Possivelmente, o manejo de percevejos realizado em soja poderá influenciar a intensidade do ataque do inseto em milho em sucessão.

A baixa densidade populacional de D. melacanthus observada em soja, no presente estudo, pode estar relacionada tanto à pulverização de inseticidas para percevejos (duas aplicações na safra I e uma na safra II), como ao tempo necessário para o desenvolvimento da população e, em parte, ao método de amostragem utilizado em soja, em que são quantificados apenas os percevejos presentes na parte aérea das plantas, enquanto, em milho, a palhada também é vistoriada.

Em soja, a densidade populacional acumulada diária (IAD) de D. melacanthus não diferiu entre os tratamentos, em ambas as safras (Tabela 3). Espera-se que o efeito do tratamento de sementes em soja seja mais efetivo nas primeiras semanas após a semeadura; em contrapartida, a infestação por percevejos nessa cultura é mais expressiva no final do ciclo. Assim, o tratamento de sementes em soja não contribui para o manejo populacional da praga, ao longo do ciclo da cultura, e não proporciona benefícios para a proteção da lavoura ao seu ataque. Isso se refletiu nos parâmetros relativos à colheita, rendimento, massa de mil grãos e percentual de massa de grãos bons, para os quais não se 
observou diferença significativa entre os tratamentos de semente de soja (Tabela 4).

Na safra II, ocorreu menos chuva durante o período de cultivo da soja, e os rendimentos foram de $56,4 \%$ dos obtidos na safra I. Apesar disso, o percentual de grãos bons foi maior na safra II. É possível que a falta de chuvas tenha afetado o período inicial da fase reprodutiva, o que causou a redução do rendimento, mas não comprometeu a qualidade de grãos. Os dados indicam que a qualidade de grãos parece ser mais influenciada por fatores climáticos do que pelo ataque de percevejos, pois, na safra II, quando a qualidade foi superior, o ataque de percevejos foi mais intenso do que na safra anterior.
Em milho, o tratamento de sementes com imidacloprido proporcionou redução de 23,2 e $38,8 \%$ da densidade populacional acumulada (IAD), em comparação à testemunha, nas safras I e II, respectivamente (Tabela 3). Os produtos tiodicarbe e tiametoxam proporcionaram redução significativa, respectivamente de 34,6 e $27,8 \%$, apenas na safra II. As notas de injúria indicam menor intensidade de ataque nos tratamentos de sementes com imidacloprido e tiametoxam, na média das quatro avaliações da safra I, e com imidacloprido na safra II (Tabela 5), o que indica que são produtos que atuam na proteção da planta ao ataque de percevejos. Martins et al. (2009) estudaram imidacloprido e tiametoxam, entre outros inseticidas

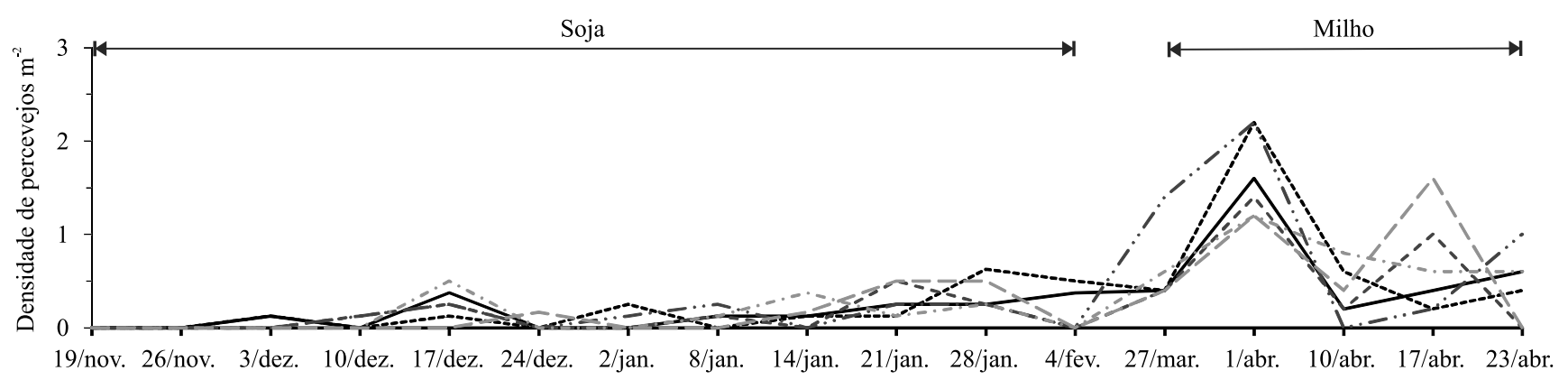

Datas de amostragem na safra I em 2012/2013

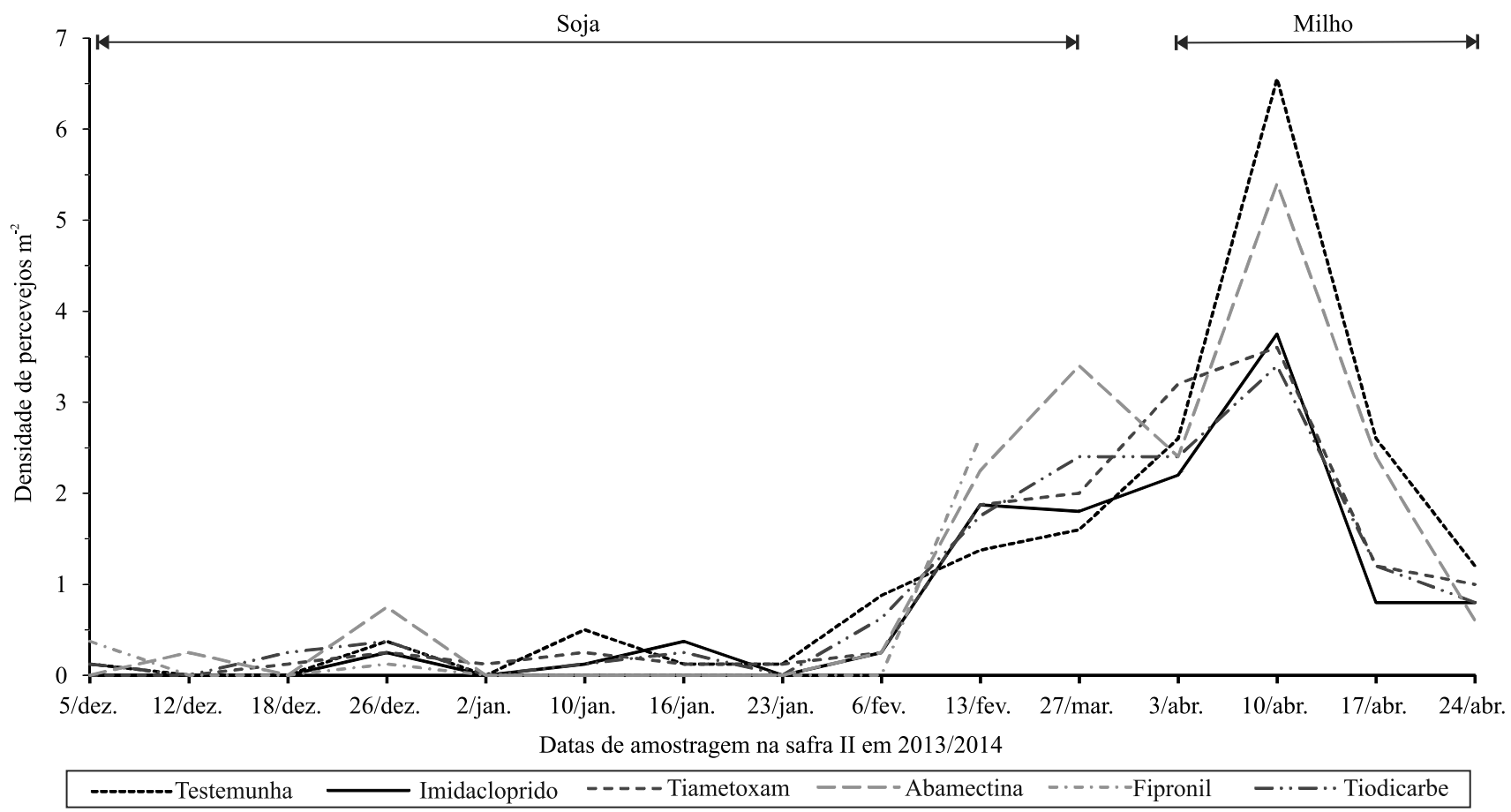

Figura 1. Flutuação populacional de Dichelops melacanthus, na sucessão cultural soja-milho, submetida a diferentes inseticidas via tratamento de sementes. Não houve diferença significativa $(p=0,05)$ entre os tratamentos em cada data de amostragem. 
aplicados em tratamento de sementes, e observaram que apenas imidacloprido reduziu a intensidade de ataque de D. melacanthus em milho. Brustolin et al. (2011), no entanto, observaram que a utilização de tiametoxam, em tratamento de sementes, proporcionou menor intensidade de ataque de D. melacanthus em milho, em comparação com a testemunha. É importante considerar que, nas condições da presente pesquisa, as notas de injúria foram baixas e não ultrapassaram a nota 2,0, em uma escala de $0-4$, ao longo de todo o período de avaliação (Tabela 5), o que indica baixa intensidade de ataque de percevejos. Em razão disso, provavelmente, não tenham sido observadas diferenças muito marcantes nas notas de injúria do tratamento com tiametoxam, em comparação à testemunha. Este produto proporcionou redução da intensidade de ataque da praga, na maior parte das datas de avaliação da safra I, porém, apenas em uma data na safra II.

Tiodicarbe proporcionou redução da injúria apenas na segunda data de avaliação, em cada safra, porém, quando analisado pela média das quatro datas de avaliação, não diferiu significativamente da testemunha. Fipronil e abamectina não contribuíram para a redução de injúria causadas por percevejos às plantas de milho. Tiodicarbe, fipronil e abamectina

Tabela 3. Densidade populacional (percevejos $\mathrm{m}^{-2}$ ) acumulada diária (IAD) de Dichelops melacanthus, em cultura de soja e milho em sucessão, submetida a diferentes inseticidas via tratamento de sementes, nas safras I em 2012/2013 e II em 2013/2014(1).

\begin{tabular}{lccccc}
\hline Tratamento & \multicolumn{2}{c}{ Safra I em 2012/2013 } & & \multicolumn{2}{c}{ Safra II em $2013 / 2014$} \\
\cline { 2 - 3 } \cline { 5 - 6 } & Soja $^{(2)}$ & Milho $^{(3)}$ & & Soja $^{(2)}$ & Milho $^{(3)}$ \\
\hline Testemunha & 11,44 & $23,70 \mathrm{a}$ & & 22,88 & $92,05 \mathrm{a}$ \\
Imidacloprido & 9,88 & $18,20 \mathrm{~b}$ & & 14,38 & $56,35 \mathrm{~b}$ \\
Tiametoxam & 8,63 & $18,90 \mathrm{ab}$ & & 16,75 & $66,50 \mathrm{~b}$ \\
Tiodicarbe & 8,56 & $23,20 \mathrm{ab}$ & & 20,19 & $60,20 \mathrm{~b}$ \\
Fipronil & 9,31 & $22,00 \mathrm{ab}$ & & 14,47 & $-(4)$ \\
Abamectina & 9,93 & $23,00 \mathrm{ab}$ & & 17,75 & $85,40 \mathrm{a}$ \\
\hline CV $(\%)$ & $10,31^{\text {ns }}$ & $13,44^{*}$ & & $13,44^{\text {ns }}$ & $8,65^{* *}$ \\
\hline
\end{tabular}

(1)Médias seguidas por letras iguais, nas colunas, não diferem entre si,

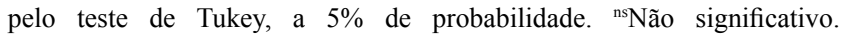
*e**Significativo a $5 \%$ e $1 \%$ de probabilidade, respectivamente. ${ }^{(2)}$ Densidade amostrada por pano de batida, ao longo do ciclo da soja, por 12 semanas, na safra I, e por 10 semanas, na safra II; houve omissão de um outlier na safra I (bloco 3 do tratamento abamectina), e outro na safra II (bloco 3 do tratamento fipronil), os dados foram transformados por $\mathrm{x}^{0,5}$. ${ }^{(3)}$ Densidade amostrada por contagem direta, durante as cinco semanas iniciais do desenvolvimento do milho, que corresponde ao período crítico da cultura ao ataque de percevejos, os dados foram transformados pelo inverso do valor $\left(\mathrm{x}^{-1}\right) .{ }^{(4)}$ Dados perdidos, em razão falhas na germinação das plantas. CV, coeficiente de variação. são produtos registrados para serem utilizados em tratamento de sementes para outras finalidades que não o controle de percevejos.

Em ambas as safras, as notas de injúria foram se reduzindo com o passar das semanas, o que indica que a planta de milho é capaz de se recuperar do ataque de percevejos (Tabela 5), como também mostrado por Roza-Gomes (2010). A capacidade da planta de milho de se recuperar de injúrias causadas pelos percevejos é corroborada pela avaliação de sua produtividade, em que, em ambas as safras, nenhum dos produtos avaliados proporcionou ganho significativo de produtividade em comparação à testemunha (Tabela 6). Esses resultados indicam que, nos níveis populacionais de percevejos ocorridos durante as duas safras do estudo, o tratamento de semente com inseticidas químicos foi desnecessário.

Os dados indicam, também, que a presença de injúria nas plantas não significa, necessariamente, que haverá perdas de produtividade da cultura, o que corrobora o observado por Roza-Gomes (2010), que não constatou redução de produtividade de milho associado a notas de injúria até 2,03 , comparativamente à testemunha sem injúria, em avaliação realizada no estádio V6 do milho. No entanto, Crosariol Netto et al. (2015) observaram ganho de $41,9 \%$ de rendimento por planta, com a

Tabela 4. Parâmetros de rendimento de soja submetida a diferentes inseticidas, via tratamento de sementes, nas safras I em 2012/2013 e II em 2013/2014(1).

\begin{tabular}{|c|c|c|c|}
\hline Tratamento & $\begin{array}{c}\text { Rendimento } \\
\left(\text { sacas ha }^{-1}\right)\end{array}$ & $\begin{array}{c}\text { Massa de mil grãos } \\
(\mathrm{g})\end{array}$ & $\begin{array}{c}\text { Massa de grãos } \\
\text { bons }(\%)^{(2)}\end{array}$ \\
\hline & \multicolumn{3}{|c|}{ Safra I em 2012/2013 } \\
\hline Testemunha & 56,15 & 132,34 & $54,23 a$ \\
\hline Imidacloprido & 56,73 & 135,73 & $51,28 \mathrm{a}$ \\
\hline Tiametoxam & 57,04 & 136,47 & $50,83 a$ \\
\hline Tiodicarbe & 56,93 & 132,28 & $54,27 \mathrm{a}$ \\
\hline Fipronil & 56,85 & 133,56 & $52,29 a$ \\
\hline Abamectina & 57,05 & 133,60 & $50,60 \mathrm{a}$ \\
\hline \multirow[t]{2}{*}{$\mathrm{CV}(\%)$} & $3,00^{\text {ns }}$ & $2,24^{\mathrm{ns}}$ & $2,23 *$ \\
\hline & \multicolumn{3}{|c|}{ Safra II em 2013/2014 } \\
\hline Testemunha & 31,81 & 119,20 & 74,68 \\
\hline Imidacloprido & 31,87 & 119,28 & 73,95 \\
\hline Tiametoxam & 32,75 & 119,84 & 74,58 \\
\hline Tiodicarbe & 32,41 & 119,08 & 73,12 \\
\hline Fipronil & 32,30 & 119,18 & 73,02 \\
\hline Abamectina & 31,01 & 118,88 & 72,94 \\
\hline $\mathrm{CV}(\%)$ & $6,13^{\text {ns }}$ & $1,94^{\text {ns }}$ & $3,51^{\mathrm{ns}}$ \\
\hline
\end{tabular}

(1) Médias seguidas por letras iguais, nas colunas, não diferem entre si, pelo teste de Tukey, a $5 \%$ de probabilidade. (2) Dados transformados por

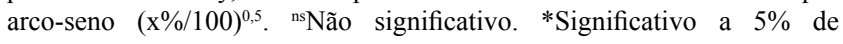
probabilidade. $\mathrm{CV}$, coeficiente de variação. 
utilização de tratamento de sementes com tiametoxam, associado à nota de ataque de 2,2 , enquanto a testemunha sem controle apresentou nota de 2,9.

É importante destacar que, no caso do presente estudo, obteve-se baixa eficiência de controle de percevejos, que foi inferior a $38,8 \%$ em todos os tratamentos e safras, isso pode ter contribuído para a ausência de aumento significativo de produtividade nas parcelas com tratamento de sementes, em comparação à testemunha. Também Ávila \& Duarte (2012) observaram baixa eficiência de controle, com o inseticida tiametoxam aplicado em tratamento de sementes de milho.

Na safra I, houve acamamento das plantas de milho, provocada por vento, o que pode ter contribuído para a menor produtividade em relação à safra seguinte. Além disso, na safra II, o milho pode ter-se beneficiado da fertilidade residual da soja que, nessa safra, apresentou baixa produtividade em razão da estiagem e, consequentemente, houve menor exportação de nutrientes do solo, que puderam ser aproveitados pelo milho cultivado em sucessão.

Tabela 5. Injúrias $^{(1)}$ ocasionadas por percevejos, em milho submetido a diferentes inseticidas via tratamento de sementes, nas safras I em 2012/2013 e II em 2013/2014(2).

\begin{tabular}{|c|c|c|c|c|c|}
\hline \multirow[t]{2}{*}{ Tratamento } & \multicolumn{4}{|c|}{ Data de avaliação } & \multirow[t]{2}{*}{ Média } \\
\hline & $04 / 04^{(3)}$ & $10 / 04$ & $17 / 04$ & $23 / 04^{(3)}$ & \\
\hline & \multicolumn{5}{|c|}{ Safra I em 2012/2013 } \\
\hline Testemunha & $1,00 \mathrm{a}$ & $1,00 \mathrm{a}$ & $1,00 \mathrm{~b}$ & $0,56 \mathrm{ab}$ & $0,89 \mathrm{a}$ \\
\hline Imidacloprido & $0,52 b$ & $0,19 \mathrm{~d}$ & $0,53 \mathrm{c}$ & $0,13 \mathrm{c}$ & $0,34 b$ \\
\hline Tiametoxam & $0,66 b$ & $0,42 \mathrm{c}$ & $0,70 \mathrm{c}$ & $0,27 b c$ & $0,51 b$ \\
\hline Tiodicarbe & $1,15 \mathrm{a}$ & $0,66 b$ & $1,17 \mathrm{ab}$ & $0,60 \mathrm{a}$ & $0,90 \mathrm{a}$ \\
\hline Fipronil & $0,99 \mathrm{a}$ & $1,12 \mathrm{a}$ & $1,14 \mathrm{ab}$ & $0,56 \mathrm{ab}$ & $0,95 \mathrm{a}$ \\
\hline Abamectina & $1,14 \mathrm{a}$ & $1,00 \mathrm{a}$ & $1,21 \mathrm{a}$ & $0,58 \mathrm{ab}$ & $0,98 \mathrm{a}$ \\
\hline \multirow[t]{2}{*}{$\mathrm{CV}(\%)$} & $9,44 * *$ & $11,13^{* *}$ & $8,77 * *$ & $30,84 * *$ & $12,80 * *$ \\
\hline & \multicolumn{5}{|c|}{ Safra II em 2013/2014 } \\
\hline Testemunha & $1,41 \mathrm{a}$ & $1,85 \mathrm{a}$ & 0,39 & $0,00 \mathrm{a}$ & $0,91 b$ \\
\hline Imidacloprido & $1,18 b$ & $1,17 \mathrm{c}$ & 0,33 & $0,02 \mathrm{a}$ & $0,67 \mathrm{c}$ \\
\hline Tiametoxam & $1,39 \mathrm{a}$ & $1,62 b$ & 0,41 & $0,07 \mathrm{a}$ & $0,87 \mathrm{~b}$ \\
\hline Tiodicarbe & $1,44 \mathrm{a}$ & $1,63 b$ & 0,41 & $0,14 \mathrm{a}$ & $0,90 \mathrm{~b}$ \\
\hline Fipronil & $-(4)$ & - & - & - & - \\
\hline Abamectina & $1,55 \mathrm{a}$ & $1,98 \mathrm{a}$ & 0,40 & $0,16 \mathrm{a}$ & $1,02 \mathrm{a}$ \\
\hline $\mathrm{CV}(\%)$ & $5,38 * *$ & $4,20 * *$ & $25,62^{\mathrm{ns}}$ & $49,96 *(5)$ & $4,79 * *$ \\
\hline
\end{tabular}

${ }^{(1)}$ Notas de injúria de acordo com escala de 0 a 4 , em avaliações realizadas a partir da segunda semana de emergência das plantas. ${ }^{(2)}$ Médias seguidas por letras iguais, nas colunas, não diferem entre si, pelo teste de Tukey, a 5\% de probabilidade. ${ }^{\text {ns }}$ Não significativo. ${ }^{*} e^{* *}$ Significativo a 5 e $1 \%$ de probabilidade. ${ }^{(3)}$ Data da primeira e última avaliação na safra II em 03/04 e 24/04, respectivamente. ${ }^{(4)}$ Dados perdidos, em razão de falhas na germinação das plantas. ${ }^{(5)}$ Dados transformados por $(\mathrm{x}+0,01)^{0,5} . \mathrm{CV}$, coeficiente de variação.
Tabela 6. Parâmetros de rendimento de milho, submetido a diferentes inseticidas via tratamento de sementes, nas safras I em 2012/2013 e II em 2013/2014(1).

\begin{tabular}{|c|c|c|c|c|}
\hline Tratamento & $\begin{array}{c}\text { Rendimento } \\
\left(\text { sacas ha }^{-1}\right)\end{array}$ & $\begin{array}{c}\text { Densidade de } \\
\text { plantas } \mathrm{m}^{-2}\end{array}$ & $\begin{array}{c}\text { Taxa de plantas } \\
\text { com espiga }(\%)^{(2)}\end{array}$ & $\begin{array}{l}\text { Massa de mil } \\
\text { grãos }(\mathrm{g})\end{array}$ \\
\hline & \multicolumn{4}{|c|}{ Safra I em 2012/2013 } \\
\hline Testemunha & $60,35 \mathrm{a}$ & 6,75 & $89,58 \mathrm{abc}$ & $196,46 a b$ \\
\hline Imidacloprido & $64,26 a$ & 6,97 & $91,52 \mathrm{a}$ & $198,04 \mathrm{ab}$ \\
\hline Tiametoxam & $62,26 \mathrm{a}$ & 6,44 & $90,40 \mathrm{ab}$ & $196,66 b$ \\
\hline Tiodicarbe & $48,93 b$ & 6,69 & $84,21 \mathrm{c}$ & $193,77 \mathrm{ab}$ \\
\hline Fipronil & $56,73 \mathrm{ab}$ & 6,78 & $85,59 \mathrm{bc}$ & $196,47 \mathrm{ab}$ \\
\hline Abamectina & $59,83 \mathrm{a}$ & 6,47 & $88,39 \mathrm{abc}$ & $200,92 \mathrm{a}$ \\
\hline \multirow[t]{2}{*}{$\mathrm{CV}(\%)$} & $7,63 * *$ & $4,34^{\mathrm{ns}}$ & $1,37 * *$ & $2,42 *$ \\
\hline & \multicolumn{4}{|c|}{ Safra II em 2013/2014 } \\
\hline Testemunha & 132,66 & 7,44 & $91,30 \mathrm{ab}$ & $300,09 \mathrm{ab}$ \\
\hline Imidacloprido & 140,09 & 7,37 & $95,81 \mathrm{a}$ & $288,29 b$ \\
\hline Tiametoxam & 139,01 & 7,27 & $90,03 b$ & $313,71 \mathrm{a}$ \\
\hline Tiodicarbe & 132,65 & 7,43 & $88,28 b$ & $304,52 \mathrm{ab}$ \\
\hline Fipronil & $-(3)$ & - & - & - \\
\hline Abamectina & 135,04 & 7,30 & $89,94 \mathrm{~b}$ & $312,61 \mathrm{a}$ \\
\hline $\mathrm{CV}(\%)$ & $3,53^{\mathrm{ns}}$ & $1,63^{\text {ns }}$ & $1,38^{*}$ & $2,98^{*}$ \\
\hline
\end{tabular}

${ }^{(1)}$ Médias seguidas por letras iguais, nas colunas, não diferem entre si, pelo teste de Tukey, a $5 \%$ de probabilidade. ${ }^{(2)}$ Dados transformados

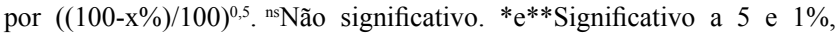
respectivamente. ${ }^{(3)}$ Dados perdidos, em razão de falhas na germinação das plantas. CV, coeficiente de variação.

Não se observou diferença estatística significativa da densidade de plantas de milho, entre os tratamentos avaliados, em todas as safras; esse parâmetro indica o efeito dos tratamentos para o estabelecimento e manutenção de um bom estande de plantas. Para a taxa de plantas com espigas, observou-se diferença entre os tratamentos, mas nenhum dos produtos proporcionou resultado superior ao da testemunha; esse parâmetro indica a contribuição dos tratamentos para a redução da ocorrência de plantas dominadas, de baixo vigor e que não produzem espigas. Imidacloprido foi o tratamento com a maior taxa de plantas com espigas e foi significativamente superior a tiodicarbe e fipronil, na safra I, e a tiodicarbe, abamectina e tiametoxam, na safra II. Nas safras, nenhum dos produtos estudados proporcionou massa de mil grãos superior à da testemunha.

\section{Conclusões}

1. Na sucessão de cultivo de soja e milho, o percevejo Dichelops melacanthus ocorre em maior densidade populacional no final do ciclo da soja e, principalmente, no início do ciclo do milho. 
2. O uso de inseticidas em tratamento de sementes não reduz a densidade populacional do percevejo D. melacanthus, ao longo do ciclo da soja; enquanto, em milho, o inseticida imidacloprido reduz a densidade populacional acumulada e a injúria causada pelo percevejo às plantas.

3. O uso dos inseticidas imidacloprido, tiametoxam, tiodicarbe, fipronil ou abamectina, em tratamento de sementes, não proporciona aumento de produtividade em soja e milho, nas condições de densidade populacional de D. melacanthus e eficiência de controle dos produtos da presente pesquisa.

\section{Referências}

ACOMPANHAMENTO da safra brasileira [de] grãos. Brasília, Conab, v.3, n.5, 2016. Safra 2015/16, quinto levantamento.

ÁVILA, C.J.; DUARTE, M.M. Eficiência de inseticidas, aplicados nas sementes e em pulverização, no controle do percevejo barriga-verde Dichelops melacanthus (Dallas) (Hemiptera: Pentatomidae), na cultura do milho. BioAssay, v.7, p.1-6, 2012. DOI: 10.14295/ba.v7.0.72.

ÁVILA, C.J.; PANIZZI, A.R. Occurrence and damage by Dichelops (Neodichelops) melacanthus (Dallas) (Heteroptera: Pentatomidae) on corn. Anais da Sociedade Entomológica do Brasil, v.24, p.193-194, 1995.

BRUSTOLIN, C.; BIANCO, R.; NEVES, P.M.O.J. Inseticida em pré e pós-emergência do milho (Zea mays L.), associados ao tratamento de sementes, sobre Dichelops melacanthus (Dallas) (Hemiptera: Pentatomidae). Revista Brasileira de Milho e Sorgo, v.10, p.215-223, 2011. DOI: 10.18512/1980-6477/rbms. v10n3p215-223.

CARVALHO, E. da S.M. Dichelops melacanthus (Dallas, 1851) (Heteroptera: Pentatomidae) no sistema de plantio direto no Sul do Mato Grosso do Sul: flutuação populacional, hospedeiros e parasitismo. 2007. 41p. Dissertação (Mestrado) Universidade Federal da Grande Dourados, Dourados.

CHOCOROSQUI, V.R.; PANIZZI, A.R. Impact of cultivation systems on Dichelops melacanthus (Dallas) (Heteroptera: Pentatomidae) populations and damage and its chemical control on wheat. Neotropical Entomology, v.33, p.487-492, 2004. DOI: 10.1590/S1519-566X2004000400014.

CHOCOROSQUI, V.R.; PANIZZI, A.R. Nymph and adult biology of Dichelops melacanthus (Dallas) (Heteroptera: Pentatomidae) feeding on cultivated and non-cultivated host plants.
Neotropical Entomology, v.37, p.353-360, 2008. DOI: 10.1590/ S1519-566X2008000400001.

CROSARIOL NETTO, J.; MICHELOTTO, M.D.; GRIGOLLI, J.F.J.; GALLI, J.A.; PIROTTA, M.Z.; BUSOLI, A.C. Damages caused by Dichelops melacanthus (Heteroptera: Pentatomidae) in conventional and transgenic corn hybrids. Bioscience Journal, v.31, p.1092-1101, 2015. DOI: 10.14393/BJ-v31n4a2015-26323.

CRUZ, I.; VIANA, P.A.; BIANCO, R. Manejo integrado de pragas. In: CRUZ, J.C.; MAGALHÃES, P.C.; PEREIRA FILHO, I.A.; MOREIRA, J.A.A. (Ed.). Milho: o produtor pergunta, a Embrapa responde. Brasília: Embrapa Informação Tecnológica, 2011. p.171-192. (Embrapa Informação Tecnológica. Coleção 500 perguntas, 500 respostas).

MARTINS, G.L.M.; TOSCANO, L.C.; TOMQUELSKI, G.V.; MARUYAMA, W.I. Controle químico do percevejo barriga-verde Dichelops melacanthus (Hemiptera: Pentatomidae) na cultura do milho. Arquivos do Instituto Biológico, v.76, p.475-478, 2009.

OLIVEIRA, M.C.N.; CORRÊA-FERREIRA, B.S. Diagnóstico exploratório na análise de dados entomológicos: efeito do diflubenzurom no consumo alimentar de Anticarsia gemmatalis (Hübner). Anais da Sociedade Entomológica do Brasil, v.27, p.627-637, 1998. DOI: 10.1590/S0301-80591998000400016.

PANIZZI, A.R.; BUENO, A. de F.; SILVA, F.A.C. da. Insetos que atacam vagens e grãos. In: HOFFMANN-CAMPO, C.B.; CORRÊA-FERREIRA, B.S.; MOSCARDI, F. (Ed.). Soja: manejo integrado de insetos e outros artrópodes-praga. Brasília: Embrapa, 2012. p.335-420.

ROZA-GOMES, M.F. Avaliação de danos de quatro espécies de percevejos (Heteroptera: Pentatomidae) em trigo, soja e milho. 2010. 93p. Tese (Doutorado) - Universidade de Passo Fundo, Passo Fundo.

ROZA-GOMES, M.F.; SALVADORI, J.R.; PEREIRA, P.R.V. da S.; PANIZZI, A.R. Injúrias de quatro espécies de percevejos pentatomídeos em plântulas de milho. Ciência Rural, v.41, p.1115-1119, 2011. DOI: 10.1590/S0103-84782011005000081.

SILVA, J.J.; VENTURA, M.U.; SILVA, F.A.C.; PANIZZI, A.R. Population dynamics of Dichelops melacanthus (Dallas) (Heteroptera: Pentatomidae) on host plants. Neotropical Entomology, v.42, p.141-145, 2013. DOI: 10.1007/ s13744-012-0104-2.

SMANIOTTO, L.F.; PANIZZI, A.R. Interactions of selected species of stink bugs (Hemiptera: Heteroptera: Pentatomidae) from leguminous crops with plants in the Neotropics. Florida Entomologist, v.98, p.7-17, 2015. DOI: 10.1653/024.098.0103.

TORRES, A.B.A.; OLIVEIRA, N.C. de; OLIVEIRA NETO, A.M. de; GUERREIRO, J.C. Injúrias causadas pelo ataque dos percevejos marrom e barriga verde durante o desenvolvimento inicial do milho. Journal of Agronomic Sciences, v.2, p.169-177, 2013.

Recebido em 27 de agosto de 2015 e aprovado em 11 de março de 2016 